\title{
EL PROYECTO UDEL Y LA LUCHA CÍVICA CONTRA LA DICTADURA: HISTORIA, ACTORES, ACCIONES Y PROGRAMA (1974-1978)
}

Miguel Ayerdis

\section{Resumen}

En este ensayo se pretende hacer un primer acercamiento, desde el punto de vista histórico, de la Unión Democrática de Liberación (UDEL), uno de los movimientos políticos anti somocistas más beligerantes surgidos en los últimos años de la dictadura (1974), cuya importancia en la lucha por el establecimiento de un nuevo régimen democrático y sus estrategias implementadas, aún son poco conocidas (estudiadas). Uno de los aspectos importantes de este trabajo, es el problematizar acerca de la construcción del discurso "oficial" o hegemónico, que en la actualidad permea las explicaciones de la última etapa de lucha del pueblo de Nicaragua contra la dictadura. En especial, se pretende poner en discusión, el papel desempeñado como oposición legal, de los movimientos, actores y figuras políticas relevantes para la época, dentro de márgenes políticos precarios establecidos por el régimen. La figura de Pedro Joaquín Chamorro, su principal promotor, ha sido destacada por la historiografía, pero el movimiento que lideró, las acciones realizadas y las contradicciones internas surgidas dentro de su movimiento y entre los sectores sociales a los que pertenecía Chamorro, aún están por estudiarse a profundidad, siendo un terreno que pude aportar a la comprensión del curso seguido por los procesos posteriores a la caída del régimen dictatorial.

Palabras claves: Unión democrática de liberación, dictadura, discurso hegemónico, movimiento político, partidos políticos.

\begin{abstract}
:
This essay aimed make a first approach from a historical perspective of the Democratic Union fo Liberation "Unión Democrática de Liberación" (UDEL), one of the most belligerent political movement against Somoza regime, in the last years of dictatorship (1974), whose importance in the fight for establishment of a democratic regime are shortly known. One aspect of this work is questioned about construction of "official" or hegemonic discourse. This paper discuss their role as legal opposition representing relevant movements, actors and politicians, considering the precarious political environment established by government. There are an emphasis in biography of Pedro Joaquin Chamorro, their main leader and promoter. However the movement, actions and internal conflict within the movement and its social sectors to which belonged Chamorro, are yet to be studied; and this is a field that can contribute to understand subsequent political process after defeated dictatorial regime.
\end{abstract}

Keywords: Unión Democrática de Liberación, dictatorship, hegemonic discourse, political movement, political parties. 
"Con la formación de la Unión Democrática de Liberación (UDEL), por primera vez en la historia nicaragüense se da el surgimiento de una nueva forma de representación política que contrastaba con las formas tradicionales que habían legitimado al somocismo por cuatro décadas." (Amalia Chamorro, 1983, Estado y hegemonía durante el somocismo)

Este criterio señalado por una de las intelectuales "orgánicas" del sandinismo en el poder a partir de julio de 1979, contiene preguntas aún no respondidas por una historiografía oficial de la Revolución (no de la lucha anti somocista que es otra cosa) que ha institucionalizado hasta hoy día, tópicos aún en uso que explican las estrategias de oposición y resistencia al régimen dictatorial de los Somoza y el triunfo de la opción armada encabezada por el FSLN. Es un relato con una visión lineal, épica (como el canto épico del FSLN de Mejía Godoy) donde las estrategias civilistas de movimientos o partidos políticos anti régimen, no encajan o al menos evidencian vacío u omisiones, quizás sea -pecando de ingenuo-- porque está diseñada bajo la lógica positivista de la historia, donde el héroe, sus batallas, son la centralidad.

En el relato de la "epopeya de la revolución" (parafraseando el título del libro de Humberto Ortega), se ha impuesto la visión histórica narrativa de la opción de la "violencia armada" (violencia revolucionaria) como eje central explicativo, cuyo discurso destaca a la generación de jóvenes con ideas marxista o nacionalistas de la década del 60 y 70, siendo el referente principal, la figura de Carlos Fonseca Amador, abanderado de la expresión triunfadora (la opción armada).

Al otro lado de la acera, refractaria a la anterior "visión heroica", están los "sobrevivientes del naufragio" (parafraseando un texto de Sergio Ramírez) memorialistas, historiadores, diletantes (Doña Violeta, Antonio Lacayo, Edmundo Jarquín, Hassán, entre otros), protagonistas o testigos algunos de ellos, desde escenarios diferentes, de los eventos que dieron al traste con la dictadura somocista. Estos autores han articulado un relato histórico testimonial, donde la gesta o "estrategia civilista" anti dictatorial, tiene un lugar preponderante en las explicaciones de ese período. Relatos pensados para un auditorio conformado por generaciones pos dictadura somocista, cuya únicas fuentes a la que han tenido acceso, para la comprensión de los episodios de este período, han sido los textos escritos por académicos, muchos de ellos provenientes del sandinismo.

Una de las argumentaciones esgrimidas por los "reivindicadores" de los movimientos articuladores de estrategias civilistas, alude a la importancia del aprovechamiento de los estrechos márgenes facilitados por la dictadura en la última década. Se argumenta que sus protagonistas expusieron sus vidas, crearon organizaciones $\mathrm{y} / \mathrm{o}$ frentes políticos y establecieron planes de lucha, e incluso pensaron en posibles escenarios de una Nicaragua y un régimen político pos Somoza (ver Diario Político de Pedro Joaquín; Vanguardia, 1989). El referente más destacado de esta estrategia fue Pedro Joaquín Chamorro, estigmatizado por los grupos de izquierda o radicales anti somocistas, como burgués, reformista y partidario de un "Somocismo sin Somoza"; por el círculo somocista y miembros de la cúpula empresarial (derecha en general) quienes lo acusaron de ser un hombre voluble a las ideas consideradas por ellos como "extremistas" o incompatible a la democracia.

El estudio de las luchas política civilista (no violenta) durante las últimas dos década del régimen de los Somoza (1960-1979), sus expresiones, actores, acciones y fines, han sido estudiadas como sucedánea (o marginales) a la perspectiva de la opción armada y las estrategias estructuradas alrededor de ella. Un ejemplo de lo que estoy señalando, es la reciente publicación del libro de María Dolores Ferrero (2012), La Nicaragua de los Somoza (1936-1979), donde el 
análisis de la situación política de Nicaragua durante las últimas dos décadas del régimen, tienen como eje central explicativo la lucha del FSLN (cuyos méritos históricos no se discuten), en menor medida y/o subordinada a la primera, los movimientos populares (de origen de izquierda o revolucionarios) y ocupando unas cuantas líneas dispersas, las agrupaciones políticas cívicas de origen socialdemócrata, de derecha anti somocista o expresiones de gremios o notables (civilistas), dentro de un extenso relato cuasi épico.

La historiografía oficial vinculada al sandinismo de finales de la década del 70 y 80, caracteriza la lucha revolucionaria de la década del 60, como una etapa de "menor represión", y de "debilidad de las organizaciones políticas autónomas de las clases populares". Reconoce que fue el momento en el que la oposición civilista expresada en los partidos tradicionales, jugó "a la oposición política, pugnando por cambiar la correlación de fuerzas del bloque hegemónico en la sociedad; [Además] logró durante tales años capitalizar el descontento popular en contra del gobierno somocista, implementando un vigoroso movimiento político". (Barahona, 1983, p. 236).

Estos criterios explicativos, vertida por otro "intelectual orgánico" del sandinismo, Amaru Barahona (1983), se sustentaba en concepto de lucha de clase, minimizando y/o criticando cualquier acción de partidos, movimientos políticos, grupos sociales o económicos, vinculados o escindidos de los partidos tradicionales, como ocurrió con UNAP, UDEL de Pedro Joaquín, o el MLC de Ramiro Sacasa Guerrero. Si bien, los intelectuales del sandinismo, reconocían el "vigoroso movimiento político" de los 60, los cuales eran achacados al boom económico del Mercado Común Centroamericano (MERCOMUN), (Vilas, 1984), la carga negativa contra el período, se explica y/o interpreta a la luz de la imposición de una genealogía de la revolución sandinista, estructurada en los albores de la lucha insurreccional y durante el gobierno revolucionario (1979-1990).

Si se parte de la ya manida máxima que sugiere que la "historia la escriben los vencedores", se puede decir que los "intelectuales orgánicos" del sandinismo, cumplieron su papel de ubicar al FSLN como el único actor legítimo (verdadero dirán en sus discursos) de la oposición al régimen, sin el cual la caída del régimen hubiese sido imposible, justificando la vía armada como la opción validada por los resultados finales. La paradoja -tal como se infiere del libro de Ferrero- es que treinta años después, teniendo mayores evidencias documentales, recursos teórico-metodológicos, se siga partiendo de tópicos y/o periodizaciones de los 70 de manera complaciente (sin mucha reflexión), en la búsqueda de explicaciones de la lucha contra la dictadura somocista y el triunfo de la revolución, conduciendo a las conclusiones por todos sabido.

De igual manera, se cae en un reduccionismo estéril el reconocer la década del 70 como el período de auge y/o confluencia de criterios entre los diferentes sectores sociales y políticos de oposición acerca de la necesidad de la opción de la violencia revolucionaria, como lo hacen algunos intelectuales del sandinismo (Chamorro, 1983), sin valorar otras estrategias de lucha también en auge. Digno de destacar en este complejo período, lleno de grandes acontecimientos, la emergencia de fuerzas opositoras civilistas, las cuales evolucionan a formas de lucha de avanzadas, como fue el caso de UDEL, MPU, para mencionar dos expresiones que surgen de núcleos antagónicos y que reflejan cambios y/o aperturas de lucha dentro de su programática y acciones.

Carlos Vila (1984) al analizar la década del 70 y el significado del surgimiento de UDEL en este período, señala:

En diciembre de 1974 se creó la Unión Democrática de Liberación 
(UDEL). Impulsada por Pedro Joaquín Chamorro, UDEL nucleaba a varios partidos y grupos políticos de clase media y mediana burguesía -Partido Liberal Independiente (PLI, Partido Social Cristiano (PSC) Acción Nacional Conservadora (ANC), Movimiento Liberal Constitucionalista (MLC)...y al Partido Socialista de Nicaragua (PSN) que de acuerdo a la línea tradicional de otros partidos latinoamericanos similares, consideraban la realización de reformas democrático-burguesa una condición necesaria para el desarrollo de un proceso revolucionario posterior. (p.215).

Pese a la marginalidad que el tema de la oposición civilista ha tenido entre los historiadores o estudiosos del tema, la mayoría de los trabajos que recogen aspectos de estas expresiones políticas, reconocen cierta beligerancia de los partidos y/o movimientos en la lucha contra la dictadura. Uno de los propósitos de este trabajo es problematizar acerca del rol jugado por la "oposición civilista" (como se auto llamaban) en especial UDEL, dentro de los estrechos márgenes de legalidad establecidos por el régimen en el período en estudio. Otro es acercarnos de manera sucinta al programa, los actores involucrados y las estrategias de lucha planteadas para alcanzar sus metas: acabar con el régimen dinástico y optar al poder.

Para iniciar debe señalarse que UDEL, como lo reconocen los intelectuales del sandinismo, representa el primer intento político interclasista, impulsado desde el seno de la burguesía nicaragüense. Su creación y composición orgánica, abre posibilidades de unificación de estrategias de lucha política, entre organizaciones, movimiento o personalidades, que años atrás hubiese sido impensable lograrlo, como fue la incorporación, bajo una única representación colectiva, de organizaciones sindicales como CTN, CGT, (las dos más importantes del país) y partidos como el Socialista con Acción Nacional Conservadora y el Movimiento Liberal Constitucionalista; movimientos campesinos, intelectuales y profesionales de diferentes signos políticos, cuyo punto de confluencia ideológica era su sentimiento anti somocista.

La conformación de la alianza UDEL en 1974 genera recelos y/o conflictos dentro la burguesía empresarial y en el seno del liderazgo de la fracción del Partido Conservador de Nicaragua. Vilas (1984) al referirse a esta situación destaca: "El Partido Conservador se resintió del intento de UDEL - particularmente de Chamorro-de querer pasar sobre él, y la gran burguesía desconfiaba de su composición pluralista y de su programa político abiertamente reformista" (p. 215)

Antes de continuar documentando las contradicciones entre los sectores económicos pudientes, afines a la oposición somocista, es pertinente destacar algunos hechos que ayuden a explicar las razones por las cuales Pedro Joaquín crea UDEL a mediados de diciembre de 1974. No fue una decisión apresurada sino planificada, obedecía a condiciones sociopolíticas particulares surgidas en los últimos dos años en el país y que Chamorro, como periodista informado y con conciencia de ser el representante de la oposición más visible (importante) en el interior del país, conocía a cabalidad.

Miembro de una de las familias aristocráticas nicaragüense afín al Partido Conservador de Nicaragua (PCN), Chamorro inicia a finales de la década del 60 la ruptura con este partido en el que militó por un breve período de tiempo (1966). Una de las razones que lo llevaron a tomar esa decisión, se debió a su oposición frontal al liderazgo de Fernando Agüero Rocha, carismático líder conservador, a quien acusaba de narcisista, autoritario y pactista. En una nota publicada en noviembre de 1968 en el diario La Prensa, deja establecida de manera clara su denuncia: 
Ni yo, ni quienes me han acompañado en esta lucha, podemos por otra parte, sancionar física o moralmente la farsa montada en el Luciérnaga (Convención conservadora para legitimar el pacto Agüero-Somoza y que Chamorro ya preveía), pues es una asamblea planeada para consumar más tarde las necesarias componendas que mantengan el régimen de los 30 años, sin lograr el cambio que el pueblo nicaragüense desea, y los conservadores que asistan están en la obligación moral de comprender y declarar la nulidad de ese acto, que no es una convención del partido, sino una reunión facciosa e irregular (Chamorro, P. J.p.12).

Al mes siguiente de ese año 1968, Chamorro anuncia en su periódico, el nacimiento del movimiento político Acción Nacional Conservadora (ANC), presentado como una corriente interna dentro del PCN. Esta nueva fracción se caracterizaba por mantener una actitud crítica hacia las políticas de alianza de la dirigencia y por la poca beligerancia de los dirigentes en su calidad de oposición política (Chamorro, 1968). Alrededor de ANC, convergen figuras opositoras de reconocida trayectoria política dentro del país, como Rafael Córdoba Rivas, Roberto Argüello Hurtado, Clemente Guido, entre otros. Años después al fundarse UDEL, el ANC será uno de las organizaciones políticas miembros de la alianza (Jarquín 1998, p.210-214).

En el año de 1969 el ANC se transforma en una fuerza política independiente del PCN y Chamorro asume el líder indiscutible, consumándose así la separación definitiva y estableciéndose dos corrientes conservadoras en el escenario político nacional. Con la mente puesta en la unidad de la oposición civilista anti somocista, el ANC se incorpora a la Alianza Cívica, conformada por un grupo de partidos, entre ellos el Movimiento Liberal Constitucionalista (MLC), Partido Social Cristiano (PSC) y el Partido Liberal Independiente (PLI). Esta Alianza política buscaba revivir la experiencia exitosa de la Unión Nacional Opositora (UNO) de 1967, la cual había logrado estructurar un frente movilizativo de amplia apertura, generado adhesiones y simpatía de una diversidad de sectores sociales, tanto dentro como fuera del país.

La Alianza Cívica se rompe a la luz del nuevo escenario político creado por el pacto Agüero-Somoza, bautizado por Chamorro como Kupia Kumi. La fracción del Partido Conservador de Nicaragua y el Partido Liberal Nacionalista llegan a acuerdos que allanan el camino a la reelección del dictador. A cambio la oposición aseguraba el establecimiento de una nueva carta magna y espacio y/o participación política dentro de la institucionalidad del Estado, incluyendo la Junta de Gobierno conformada para gobernar, mientras se instalaba la Asamblea Nacional y se redactaba la nueva Constitución. Como se constará tiempo después, la efímera constitución del 74 sería un engendro hecho a la medida del régimen.

En un editorial fechado 28 de julio de 1971, Chamorro, hace un balance de la Alianza Cívica, donde sin hacer una mención explícita, reconoce lo intrascendente de esta coalición opositora, la cual nunca tuvo arraigo entre la población, ni estructuró un programas atractivo para los diversos sectores sociales. Reconocía que las organizaciones miembros estaban en contra de los pactos y del zancudismo (oposición formal que buscaba prebendas del régimen a cambio de su legitimación). Además, creía necesaria la búsqueda de nuevos métodos de lucha, diferente a los usados de manera tradicional contra el régimen:

Lo importancia es variar de método y quizás la crisis de la oposición manifestada en la ruptura tanto de la Alianza Cívica como del CON (Coalición Opositora Nacional), dará paso a una nueva metodología, capaz de producir el fenómeno anhelado por los nicaragüenses. 
Decimos todo lo anterior refiriéndonos de manera estricta a la que bien podría llamarse la "oposición formada en cauces tradicionales", es decir, los distintos partidos o movimientos políticos que han actuado en el escenario nacional durante 10 o 15 años. Pero si hiciéramos una extensión a sectores juveniles, obreros, y otros de clase media no agrupados ni comprometidos con la política tradicional, nos encontraríamos con el fenómeno de que la gran mayoría de nuestros ciudadanos, están definitivamente en contra del régimen establecido... (Chamorro, P. J. p. 2)

Esta nueva concepción vislumbra el interés de Chamorro de abrir su iniciativa a otros sectores políticos y sociales, reflejando un cambio en la concepción política de este líder opositor. Es importante mencionar la evolución experimentada, desde el punto de vista de las estrategias de lucha política y de su ideología. Aunque debe de trabajarse más, podría decirse de manera provisional, que existe un Pedro Joaquín anterior a la acción de Olama y Mollejones (1959), otro anterior al pacto Kupia Kumi (1971) y uno después de UDEL (1974).

Estamos frente a un figura pública que de joven creía en la metodología política de la oposición tradicional (PCN y diferentes fracciones), incluyendo algunos períodos de aventuras armada como opción política frente al régimen; asume el ideario social cristiano (sin decirlo de manera explícita) en la década del 60, incorporándolo al programa del PCN y al ANC. Un ideario que puede ayudar a explicar esa conversión en su ideario político, de renovación doctrinaria (demócrata cristiana), de pluralidad y de apertura, expresada como necesidad política desde los inicios de la década del 70.

En febrero de 1972 se realizó la farsa electoral de la Asamblea Constituyente, en consonancia con el pacto Agüero-Somoza del año anterior. Ante el vacío y la desolación de la oposición civilista, Chamorro asume el liderazgo desde el diario la Prensa, denunciando la ilegitimidad de este proceso, alertando lo pernicioso que esa Asamblea le trae al país y denunciando la complicidad de la oposición conservadora, liderada por Agüero Rocha. La abstención y el poco respaldo a los conservadores, le lleva a señalar que esas elecciones representaban un referéndum para el Partido Conservador de Nicaragua:

$$
\begin{aligned}
& \text { El referemdum del domingo }(6 \\
& \text { de febrero) pasado demostró la } \\
& \text { impopularidad de los pactos Agüero- } \\
& \text { Somoza y sirvió especialmente para que } \\
& \text { el repudio total al primero de ellos por } \\
& \text { parte de la ciudadanía en general y del } \\
& \text { Partido Conservador de Nicaragua en } \\
& \text { particular, se patentizara más. }
\end{aligned}
$$

Los somocistas hicieron lo suyo, eso nadie lo pone en duda, presionando, pidiendo mostrar votos, repartiendo magníficas, etc., nada nuevo, pero el otro fenómeno, es decir, el de la abstención en la casilla verde, por notable y aplastante, sí que es un fenómeno nuevo y relevante. (Chamorro, P. J. p. 2)

El ideario de unidad y la necesidad de conformación de una coalición opositora amplia, es planteada en el editorial del 12 de noviembre de 1972, poco antes del trágico terremoto que marcara las vidas de la generación de nicaragüenses de esa época. En el editorial Chamorro, prefigura las bases que dos años después sustentarán los principios de creación de UDEL: unidad nacional, liberación nacional, RESISTENCIA (escrita en mayúscula), movilización nacional. $\mathrm{Al}$ final señala:

La oposición por consiguiente debe y puede pasar de la etapa actual a otra de resistencia organizada y consolidada y eso se logra no solamente limando asperezas y produciendo entendimiento entre los diferentes grupos políticos, gremiales, ciudadano que ya está harto de abusos y atropellos. (Chamorro, P. J. p. 2) 
Como se ha señalado, cuando se da la fundación de UDEL, PJCH estaba consciente de la crisis política y social que enfrentaba el régimen. Las acciones del FSLN, la presencia estudiantil en las calles, los movimientos cristianos identificados con la teología de la liberación y la conciencia de gremio dentro de los trabajadores de la construcción, salud, maestro entre otros, era un reflejo de la difícil situación política que vivía el país, y preludio de los brotes de violencia política que se avecinaba.

Pese a la publicidad oficial y de sectores económicos afines al régimen, quienes se aferraban a los supuestos beneficios del MERCOMUN, en crisis a principios de la década del 70 , la realidad vivida por la mayoría de la población era distinta: las disparidades en la distribución del ingreso era palpable en el acceso a bienes y servicios, entre una clase alta y media, relativamente pequeña y una enorme mayoría de pobres asalariados, trabajadores informales y desempleados. La migración campo ciudad seguía creciendo, y los cinturones de miseria con barrios marginales estaban por todos lados.

En el año de 1972 se dan a conocer dos estudios realizados por dos instituciones conocidas organizaciones no gubernamentales, donde se exponía con objetividad la situación social precaria en que vivía la mayor parte de la población nicaragüense: uno de esos estudios fue realizado por un equipo de sociólogos de la UCA, titulado, "Seminario de marginalidad. Esquema de estudio de barrio", el cual fue presentado a académicos, organizaciones civiles y ONG. El estudio hacía una radiografía de la vida de los habitantes, del populoso barrio marginal (para esa época) conocido como "Reparto Schick", situado al sur de la capital. El otro estudio era más amplio y fue realizado por un equipo interdisciplinario del Instituto de Promoción Humana (INPRHU) coordinado por su director y fundador, Reynaldo Antonio Téfel, reconocido opositor al régimen, amigo personal de Chamorro, llevaba por título “El infierno de los pobres: diagnóstico sociológico de los barrios marginales de Managua".

Ambos estudios alertaban a los políticos y empresarios de la situación social que vivía la mayor parte de los habitantes de la capital, sin acceso a los servicios básicos, agua, vivienda, salud, empleo, lo cual era un reflejo del país. Sin decirlo de manera abierta, dejaban sentada la responsabilidad del gobierno y de sus sostenedores: "Estos son los pobres de Managua. Los marginales. Carne de elecciones, plataforma de propagandas presidenciales, masas de manifestaciones y siempre olvidados a la hora de los banquetes y de la repartición. El Estado-botín definitivamente no es para ellos" (Téfel; p.10).

El terremoto del 23 de diciembre de 1972 que destruyó la capital, creaba un nuevo escenario político y social, aprovechado por Chamorro de manera creativa. Por medio de su periódico, acentúa las denuncias de corrupción del régimen, en especial con la ayuda para los damnificados del terremoto, haciendo reportajes gráficos y testimoniales, del desamparo en que se encontraba la población afectada por la tragedia: desempleada y sin ayuda clama por una ración de alimentación, refugio decente y ayuda para reconstruir sus viviendas, frente a la indiferencia del régimen.

Las periodizaciones realizadas por los intelectuales de filiación sandinista, quienes estructuraron una explicación de la revolución sandinista teniendo como protagonista al FSLN, han calificado el año de 1974 como la "ruptura de la acumulación de fuerzas en silencio", representada por la acción del Comando Juan José Quezada y la toma de la Casa de Chema Castillo, el 27 de diciembre. Acontecimiento armado que ha quedado como referencia en la lucha anti somocista, invisibilizando y/o marginando otros eventos de gran importancia para la historia reciente, como las protestas 
emprendidas por el “Grupo de los 27", ante la puesta en vigencia de la nueva Constitución y farsa electoral de septiembre de ese año. Tampoco se destaca la fundación de UDEL a mediados de diciembre, como una nueva forma de lucha de los grupos opositores que hasta ese momento, creían en las luchas cívicas, dentro de los estrechos márgenes que daba el régimen.

Como se señaló, en Septiembre del 74 se realizaron elecciones presidenciales, siguiendo el calendario elaborado por los asambleístas de la Constituyente de 1972 (prevista en los pactos Agüero-Somoza o kupia Kumi de 1971). Fueron los últimos comicios realizados por la dictadura, y lo que más se recuerda, son las denuncias documentadas por Chamorro, desde su periódico, de las grandes irregularidades. Meses antes, Chamorro había respaldado de manera abierta las denuncias del "Grupo de los 27", conformado por figuras notables, quienes desde marzo de ese año habían iniciado una campaña nacional de abstención, argumentando que esas elecciones, no representan la voluntad del pueblo al ser una farsa para continuar reforzando la dictadura. La campaña tendrá el slogan "No hay por quién votar" (Chamorro, P. J. p. 2). Esta campaña hace que el régimen entable un juicio a los miembros del Grupo, entre ellos a Pedro Joaquín Chamorro, por considerar que esa campaña atentaba contra la institucionalidad del país, al que calificaba como delito.

En anterior contexto, es el fundamental para entender la creación de la alianza opositora UDEL. Días antes de su fundación, Chamorro por medio de su espacio de editorial del diario La Prensa, anuncia la creación del grupo político. En la edición del 11 de diciembre aparece el editorial titulado: "Una salida: empresarios, intelectuales y pueblo", parafraseando al poeta José Coronel Urtecho, quien semanas antes, había exhortado, por medio de una conferencia dada a los empresarios, a la unidad para enfrentar la situación de "estancamiento" del país. Chamorro va más allá y plantea una unidad donde participen las "fuerzas populares", los intelectuales, en una "pluralidad armónica", pidiéndole a los empresarios que dejen el miedo y se integren (La Prensa, 1974, p.2).

En el editorial de día siguiente, anuncia el mitin donde se constituirá UDEL como nueva fuerza opositora cuyo principio básico es la búsqueda de la unidad de toda la oposición al régimen. Para ello apelaba a un programa progresista, donde se construya una "inmensa fuerza popular":

Mayor razón que nunca existe ahora para asistir al mitin del próximo domingo 15 en la ciudad de Masaya. El mitin donde se va a suscribir la unidad de la oposición sobre bases concretas; asentada en un programa mínimo de coincidencias básicas.

Asentada en un programa progresista, democrático, y realista, con lo cual queremos significar también su carencia de extremismos imposible...Se debe ir porque éste es el primer paso verdadero dado a fondo, en la construcción de una inmensa fuerza popular -obreros, políticos, profesionales, intelectuales, clases mediasúnica maquinaria capaz de enfrentarse con éxito a la maquinaria opresora del sistema (Chamorro, 1974, p.2).

La iniciativa de UDEL refleja la voluntad de apertura y tolerancia a la pluralidad ideológica de los líderes y/o movimientos que conformaban la coalición opositora, aunque hay que reconocer que tiempo después, algunos líderes fundadores se separarán ante prejuicios derivados de concepciones ideológicas estrechas y/o rivalidades internas en sus partidos. El programa de esta coalición y la composición de la misma, fue mal visto por los partidos tradicionales de derecha, como la fracción del Partido Conservador de AgüeroPaguagua y por los sectores de izquierda, 
entre como el Partido Comunista, MAP-ML, el FSLN, y los gremios de empresarios. Las diversas corrientes de izquierda tildarán este esfuerzo político como un esfuerzo más de la burguesía por establecer un régimen democrático burgués, el cual se resumía en la consigna: "no al somocismo sin Somoza".

Los sectores empresariales de origen filiación conservadora, y otros opositores anti somocistas, tenían doble razón para rechazar el proyecto de UDEL. Por un lado, la inclusión del Partido Socialista de Nicaragua a la coalición, generaba rechazo dada su condición de clase y la formación anticomunista de sus miembros. Pero también sentían temor de perder sus privilegios frente al régimen, si se acercaban a la coalición. Esta última posición fue denunciada por Chamorro en su editorial del 11 de diciembre de 1974:

Es verdad que nada se puede hacer sin la participación de la empresa privada, como tampoco si se trata de soluciones profundas y verdaderas, pueden llevarse a cabo éstas, sin el concurso de los intelectuales, pero también es cierto que una empresa privada sometida al feudo, aterrorizada por las amenazas impositivas, halagada con las exenciones y "estímulos industriales", obligada a ser parte de la corte del señor feudal, polarizada junto a él por una irracional desconfianza hacia los sectores populares, también es cierto decimos, que una empresa privada en esas condiciones no pueden ser agentes positivos, en la búsqueda de una salida al estancamiento actual (Chamorro, 1974, p.2).

El proyecto y naturaleza de UDEL es dado a conocer por Pedro Joaquín en un editorial de La Prensa, una semana después de la fundación oficial en Masaya, donde califica al nuevo movimiento como un esfuerzo político que va más allá de un "objetivo electorero": "la liberación nacional". Si bien recogía las aspiraciones de unidad, de alternativa, también establece el método para llegar al poder: la resistencia cívica y organizada contra el régimen. En este punto aclara las formas de lucha para alcanzar el poder: "la resistencia cívica en los tribunales, en las tribunas y en las calles. La resistencia cívica en toda tarea diaria. En los talleres, en las empresas, en el campo, en la ciudad, en los patios como éste, en las plazas y en las calles" (Chamorro, 1974, p. 2)

Para concluir es imperativo señalar que la historiografía de la época y la actual, han omitido o abordado de forma marginal el papel de las luchas cívicas contra la dictadura, como el movimiento de UDEL y de su líder Pedro Joaquín Chamorro. Un movimiento que aglutinó a fuerzas políticas amplias dentro de una concepción nueva de unidad opositora que tuvo su correlato con la apertura de alianza que la tendencia tercerista del FSLN realiza a finales de 1977, con el grupo de Los Doce, el Movimiento Pueblo Unido y otros.

Los movimientos cívicos en diferentes momentos de la larga dictadura de los Somoza (1937-1979), tuvieron una presencia importante en las estrategias de lucha contra el régimen. Muchos de estas expresiones fueron reprimidas, perseguidos sus líderes o limitadas sus acciones. Hace falta llenar los vacíos y aclarar explicaciones fáciles y repetitivas sobre algunos episodios de la historia reciente de Nicaragua, de los actores, estrategias e influencia que estos movimientos, coaliciones o partidos políticos tuvieron durante el período en estudio, con el fin de contribuir a una explicación más completa y plural de los mismos.

\section{Referencias bibliográficas}

-Barahona, A. (1983) Intervención extranjera y dictadura. En Lanuza, A., Vázquez, J. L., Barahona, A., Chamorro, Economía y sociedad en la construcción del Estado en Nicaragua. San José: ICAP. 
-Chamorro, A. (1983). Estado y hegemonía durante el somocismo. En Lanuza, A., Vázquez, J. L., Barahona, A., Chamorro, Economía y sociedad en la construcción del Estado en Nicaragua. San José: ICAP.

-Chamorro, P. J. (1968, 3 de noviembre) Podríamos destruir la farsa pero dañaríamos a inocentes. La Prensa, p.12.

(1968, 21 de diciembre) Primeros frutos de la "Nueva Alternativa". La Prensa, p.2 (1971, 28 de julio). La ruptura de la Alianza. La Prensa, pág. 2. -- (1972, 10 de febrero). Derrota contable y también moral. La Prensa, p.2.

(1972, 12 de noviembre). La unidad y la resistencia, La Prensa, p.2.

Nicaragüenses: Recordemos, y digamos no..!. La Prensa, p. 2

(1974, 3 de septiembre). Somoza repudiado debe renunciar. $\mathrm{La}$ Prensa, p.2.

(1974, 5 de septiembre) La debacle y la vergüenza". La Prensa, p. 2.

(1974, 12 de diciembre) Ahora es más necesario ir a Masaya el domingo. La Prensa, p. 2
(1974, 11 de diciembre) Una salida: empresarios, intelectuales y pueblo. La Prensa, p. 2.

- (1974, 18 de diciembre de 1974) Un resumen claro de lo que es UDEL. La Prensa, p. 2)

-Ferrero Blanco, M. D. (2012) La Nicaragua de los Somoza (1936-1979). Managua: IHNCA-UCA.

-Jarquín Calderón, E.(1998). ¡Juega!.Managua: Ediciones Centroamericanas.

-Ortega Saavedra, H. (2004) La epopeya de la insurrección. Managua: Lea Grupo Editorial)

-Ramírez, S. (1987) Las armas del futuro. Habana: Editorial de Ciencias Sociales.

-Tefel, .R.A. (1976). El infierno de los pobres. Diagnóstico sociológico de los barrios marginales de Managua. Managua: Ediciones El Pez y la Serpiente.

-Vilas, C. M. (1984) Perfiles de la revolución sandinista. La Habana: Cuba.

(1989) Transición desde el subdesarrollo. Revolución y reforma en la periferia. Caracas: Editorial Nueva Sociedad.

-Seminario de marginalidad: Esquema de estudio de barrio (1972). Managua, Universidad Centroamericana. 